\title{
Studies of Humic Acid Removal from Aqueous Systems by Using Polymeric Membrane Ultrafiltration Process
}

\author{
LAURENIU TATARU ${ }^{1}$, VALENTIN NEDEFF ${ }^{1,2}$, NARCIS BARSAN ${ }^{1 *}$, EMILIAN MOSNEGUTU ${ }^{1}$, MIRELA PANAINTE LEHADUS ${ }^{1}$, \\ ION SANDU ${ }^{3,4}$, DANA CHITIMUS ${ }^{1}$ \\ ${ }^{1}$ Vasile Alecsandri University of Bacau, Department of Environmental Engineering and Mechanical Engineering, 157 Calea \\ Marasesti, 600115, Bacau, Romania \\ ${ }^{2}$ Academy of Agricultural and Forestry Sciences Gh. Ionescu Sisesti, 61 Marasti Blvd., 011464, Bucharest, Romania \\ ${ }^{3}$ Alexandru Ioan Cuza University of lasi, ARHEOINVEST Interdisciplinary Platform, 22 Carol I Blvd., 700506, Iasi, Romania \\ ${ }^{4}$ Romanian Inventors Forum, 3 Sf. Petru Movila Str., 700089, Iasi, Romania
}

\begin{abstract}
This paper proposes to investigate in detail the behavior of polymeric membranes ultrafiltration process uses in the retention of humic acid from aqueous systems. Nowadays, the aqueous systems (contaminated water and/or wastewater) resulting from various domestic and industrial activities contain many contaminants, some of them increasingly dangerous to the environment. Laboratory testing of membranes in the ultrafiltration process as well as their experimentation with different chemical compounds is essential because it is important to know how they can be eliminated before they cause a negative impact. Testing of polymeric membranes consists in carrying out the process of ultrafiltration of aqueous systems containing humic acid over a set time, following the variation in time of the volume of permeate obtained as well as the influence of process parameters. Following the investigation of the ultrafiltration process of the water through the polymeric membrane, it was found that the formation of the humic acid layer on the surface of the membrane that favors fouling is delayed, after many hours of operation, due to both the internal fiber structure which offers advantages to this type of membranes as well as high efficiency of humic acid retention. Experimental results showed that the humic acid retention rate increased by up to $37 \%$ as a result of the double decrease of the conductivity value in the permeate samples from about $600 \mu \mathrm{S} / \mathrm{cm}$ to $373 \mu \mathrm{S} /$ $\mathrm{cm}$ and the temperature being continuously increasing, from 22.5 at $25^{\circ} \mathrm{C}$ over $5 \mathrm{~h}$ influenced the entire ultrafiltration process. The full process approach as well as the expression and interpretation of the results will be detailed in this paper.
\end{abstract}

Keywords: efficiency, polymeric membranes, humic acid, polyacrylonitrile, ultrafiltration

Low pressure membrane technology has become the most handy solution to meet the water requirements for consumption in different directions: in the food industry for beverages and drinking water treatment [1] where the osmosis process is needed, because the energy consumption is low but the quality of the permeate obtained is high [2]. The most common processes that are effective and operating at low pressures made up of the membrane module are microfiltration and ultrafiltration, and reverse membrane washing is increasingly being used on an industrial scale [3]. Such method can be alternative to the energy consuming plasma filtration so far with numerous applications in various fields including medicine [4].

Like any process that serves in the filtration process and is based on the membrane, foulling remains the most worrying disadvantage in ultrafiltration as a result of wetting the membrane [5-7].

In this context, foulling occurs in two forms: first, if the matter particles are larger than the dimensions of the membrane pores, then the material is deposited on the surface of the membrane, forming a crust that can be removed more easily [8]. Secondly, if the particles are smaller than the membrane pores and here we mention the humic substances, the proteins, etc., they are easily deposited on the pore walls blocking them and decreasing the filtration efficiency, but the method of membrane cleaning is more difficult $[9,10]$.

Humic acid results from the process of natural decomposition of both animals and plants and exists all over the Earth due to the fact that decomposition is a continuous process [11].
The presence of humic acid in natural waters differs as a concentration, ranging from a few $\mathrm{mg} / \mathrm{L}$ to hundreds of $\mathrm{mg} / \mathrm{L}$. Due to the high concentration of humic acid in surface waters, its smell and color intensify [12], also causing environmental problems because in contact with heavy metals in water the concentrations of these substances increase significantly and make visible the natural receptor pollution [13]. In order to eliminate humic acid from the aqueous systems, ultrafiltration membranes are very suitable because the pore size is excellent, which makes the particle retention better outlined $[14,15]$.

The organic membrane ultrafiltration process can be successfully completed if the filtered water has previously undergone a microfiltration, or classic processes such as flocculation, ozonisation, disinfection with sodium hypochlorite, etc., to produce potable water [16-25].

The interest of adopting membrane technology in recent years has increased due to their many advantages, but one of the most important is that membranes do not alter the qualitative properties of water but on the contrary keep them in good condition [26, 27].

Some research has highlighted the advantages of adsorption of wastewater containing humic acid and found that some adsorbents possess high adsorption capacity due to its high maturation effects [28] and the results showed that the presence of adsorbents in the pretreated water had revealed a much less visible of the membrane [29].

It would be ideal to study ultrafiltration membrane behavior in retention of humic acid in combination with inorganic salts because the foulling of the membrane

* email: narcis.barsan@ub.ro; Phone: +40742325012 
during the process occurs as a result of the concentration of these salts, and through these salts it can be noticed how high the influence of the presence of humic acid in the supply water [11, 12, 26-31].

Researchers such as Q.L. Li and M. Elimelech [32] confirm that the presence of cations in the feed solution causes the foulling of the membrane to be diminished but also accelerated, but on a case-by-case basis a certain concentration of $\mathrm{Na}^{+}$can lead to an acceleration of the membrane soiling, respectively a low flux permeate.

The present study investigates de possibilities of humic acid removal from aqueous systems by using polymeric membranes ultrafiltration process.

\section{Experimental part}

Schematic of the experimental plant with the components

The installation from figure 1 were used in the ultrafiltration process of aqueous systems with different concentrations of chemical compounds, including humic acid (in the case of this paper).

The flow control valves regulate the flow of liquid entering the system circuit as well as the flow of the concentrate and the permeate obtained from the filtration. The control panel (fig. 1a ) shows the input signal of the power supply in the system, indicates the pressures that occur as a result of the liquid entering the membrane module, ie the pressure from the concentrate and the permeate. At the same time, the panel displays the temperature, and it can be adjusted and maintained at an established interval before the proposed ultrafiltration process begins. The speed of the pump can be adjusted by means of the Speed button on the panel, which has 10 pump speeds [33].

Use of materials in the ultrafiltration process

Preparation of humic acid in aqueous system

Humic acid was purchased from Sigma-Aldrich Chemie Company, mixed with deionized water, in a $1 \mathrm{~L}$ flask, homogenized by means of a stirrer subjected to a rpm of $400 \mathrm{rpm}$ for $10 \mathrm{~min}$, so that the acid humic to become an emulsion before combining with the tap water in the supply tank (fig. 1e).

Finally, a concentration of $4 \mathrm{~g}$ of humic acid was obtained per liter of tap water. The solution obtained was introduced into the supply tank containing $40 \mathrm{~L}$ of water, filtered through two filters: one of the activated carbon and one of the organic matter (fig. 1h), both of which have a pore size of $0.45 \mu \mathrm{m}$, so that the particles with higher symmetries do not penetrate into the membrane, thus avoiding the risk of membrane degradation.
The use of the polymeric membrane module in the ultrafiltration process

In the experiments performed in this paper, the membrane module has the following characteristics (fig. 1c) [33]:

-the effective filtration area is $0.6 \mathrm{~m}^{2}$, equivalent to $60000 \mathrm{~cm}^{2}$ :

-a cylindrical polysulfone casing incorporating the fibers along its length;

-dimensions: internal dimension of the fibers: $0.8 \mathrm{~mm}$, outer size: $1.4 \mathrm{~mm}$, pore size: $0.01 \mu \mathrm{m}$;

-the first flow mode: transverse flux (perpendicular to the direction of pore orientation);

-the flow rate of liquid through the membrane module during the ultrafiltration process: $\approx 90 \mathrm{~L} / \mathrm{h}$, if the transmembrane pressure is 1 bar.

-the molecular weight of the membrane is $13 \mathrm{kDa}$.

Procedure for using the polymeric membrane plant in the ultrafiltration process to reduce humic acid from aqueous systems

The module containing the polyacrylonitrile hollow fiber membrane is tested to retain humic acid on the surface of the membrane or to see how much of its initial concentration is removed by the concentrated portion that recirculates in the feed tank.

By adjusting the speed on the control panel, the LOWARA 3SV08F00TT/D (fig. 1b) [26] pump allows the fluid to enter the membrane with a certain flow, which means the pressure change both at the membrane inlet and the pressure from concentrate and permeate.

With humic acid retention on the surface of the membrane, it is expected that the volume of the permeate obtained will decrease, butalso the feed rate will gradually decrease because the fouling of the pores in the membrane implies the stopping of the liquid passage, respectively a decreasing amount of the permeate.

The flow of liquid from the installation, which penetrates into the diaphragm module, is regulated by means of the flowmeter (fig. 1i), as well as the permeate obtained (fig. lg).

A very important parameter in the ultrafiltration process is the temperature $[2,3,14,29]$ because the acceleration of the liquid through the plant due to the increase in the pressure or clogging of the membrane implies its heating, respectively the temperature rise.

The MP 90 ultrafiltration plant is equipped with a thermal metal column (fig. 1j), which allows the selection of the temperature range prior to the start of the filtration, respectively the solution passing through the plant

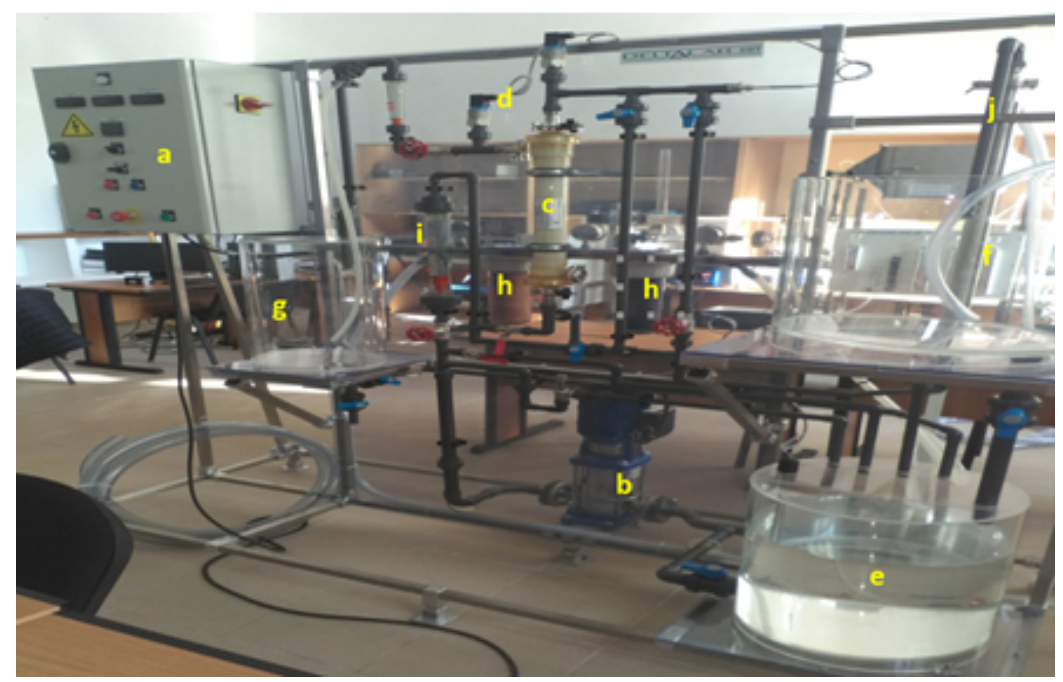

Fig. 1. The experimental ultrafiltration plant located at Vasile Alecsandri University of Bacau [33]:

a. control panel; b. peristaltic pump; c. membrane module; $d$. pressure sensors; e. feed tank; $f$. concentrate tank; g. permeate tank; $h$. carbon filter and organic filter; i. flowmetter; j. thermal metal column 
maintains the same temperature throughout the process until it is completed.

Permeate harvesting will be done every $30 \mathrm{~min}$ to analyze the permeate volume curve obtained over time. At the same time the samples taken for analysis will be analyzed, the values of the essential parameters will be measured, the liquid flow curve will be determined as a result of fouling of the membrane, temperature recording to see how long the thermal resistance of the liquid to the desired temperature is required.

Parameters such as conductivity, turbidity, $\mathrm{pH}$ and pressure fluctuations $[2,9,19,26]$, after the analyzed samples will indicate the degree of membrane humic acid retention capacity as well as the time period during which the membrane can be successfully used in the ultrafiltration process of humic acid removal from an aqueous system $[11,13,19,29]$.

Each sample of the permeate will be analyzed as well as sample solutions from the feed tank to compare the humic acid concentration before and after the start of the ultrafiltration process.

The membrane fouling process is expected to occur after several hours of operation of the plant because the humic acid particles are larger in size than other substances, which means a great rejection, respectively, humic acid is deposited on the walls of the membrane pores in a longer time.

\section{Results and discussions}

The ultrafiltration process was carried out without interruption within 5 hours at a transmembrane pressure of 0.75 bar, calculated with the relation [33]:

$$
P T M=\frac{P 1+P 2}{2}-P 3
$$

where: PTM is the transmembrane pressure (bar); P1 - the pressure recorded at the inlet of the liquid flow into the membrane; P2 - concentrate pressure; P3 - the pressure of the permeate.

The data were collected every $30 \mathrm{~min}$ and the permeate samples and the feed liquid samples before and after the ultrafiltration process were analyzed accordingly.

At the transmembrane pressure of $0.75 \mathrm{bar}$, the initial flow was $1000 \mathrm{~L} / \mathrm{h}$ (fig. 2). However, the pressure remained unchanged throughout the process, both permeate and concentrate. This flow has decreased from the first 30 minutes, 2-3 $L$ after each time interval, finally reaching $980 \mathrm{~L}$ over $5 \mathrm{~h}$ of experiment.

This decrease is primarily due to the fouling of the humic acid membrane, since it has larger particle size compared to other substances such as yeast, which means a pore lock on the surface of the membrane, not on the pore walls.

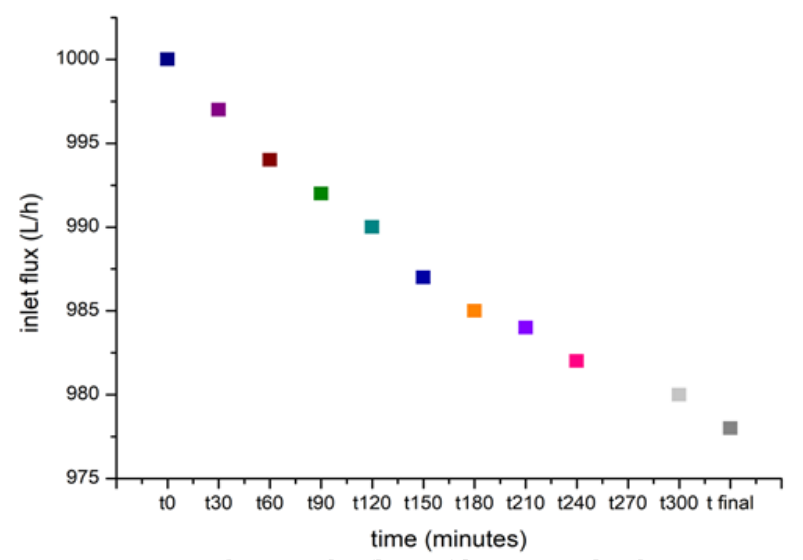

Fig. 2. Membrane inlet flow of humic acid solution
Under no circumstances the feed flow in the membrane cannot remain constant because the membrane, regardless of its type, performs the filtration process. Regardless of the fact that the membrane holds more or less the filtered substance, the flow will always fluctuate more or less.

Flow density was measured with relation [33]:

$$
J=\frac{Q}{S}
$$

where: $J$ is the flow density, expressed in $\mathrm{m}^{3} / \mathrm{s} / \mathrm{m}^{2} ; \mathrm{Q}$ Permeate flow rate measured in unit of time, expressed in $\mathrm{m}^{3} / \mathrm{s}$; S - the effective membrane filtration surface.

As a result of the density measurement, the value was $0.00066 \mathrm{~m}^{3} / \mathrm{s} / \mathrm{m}^{2}$.

The volumetric concentration factor for the experiments performed was 1.03. This was determined with relation [33]:

$$
F C V=\frac{\text { initial volume }}{\text { initial volume }+ \text { volume of permeat }}
$$

In figure 3, the volume of permeate decreased as the feed stream dropped. For both cases, respectively, the decrease in the feed flow and the permeate volume, the main reason is the membrane soiling due to the deposition of humic acid on the filtration surface thereof.

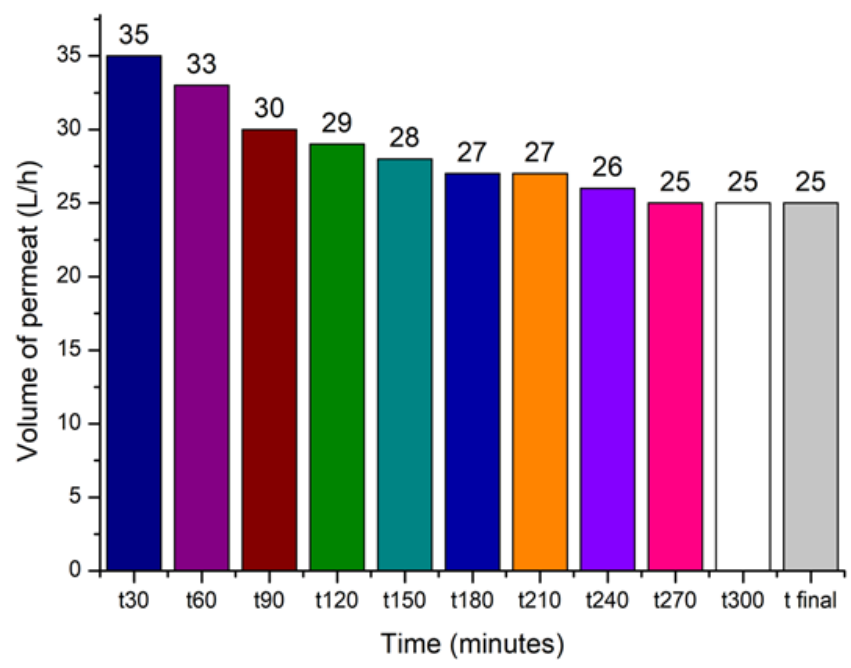

Fig. 3. Volume of permeate obtained after $300 \mathrm{~min}$ of humic acid filtration

After the first $90 \mathrm{~min}$, the volume of permeate dropped further by $5 \mathrm{~L}$, and then it decreased less, since after min 120 , the volume of permeate recorded decreased by only one liter after 30 min of operation of the membrane or remain the same as shown between minutes 180-210 and 270-300 respectively.

Regardless of the increase or decrease of the flux, in an ultrafiltration process by which a membrane is used, the temperature will be increased due to the liquid circuit through the plant.

The ultrafiltration process of aqueous systems containing humic acid started at $22.5^{\circ} \mathrm{C}$ (fig. 4). It varied continuously, increasing on average by about $0.5^{\circ} \mathrm{C}$ after every 30 min of filtration.

As can be seen in figure 4, after $210 \mathrm{~min}$, the temperature tends to remain somewhat constant, with small variations of fluctuation. This shows that with the decrease of flow of liquid entering the membrane, respectively with the decrease of the permeate, the speed of water displacement decreases, gradually decreasing the heating phenomenon. 


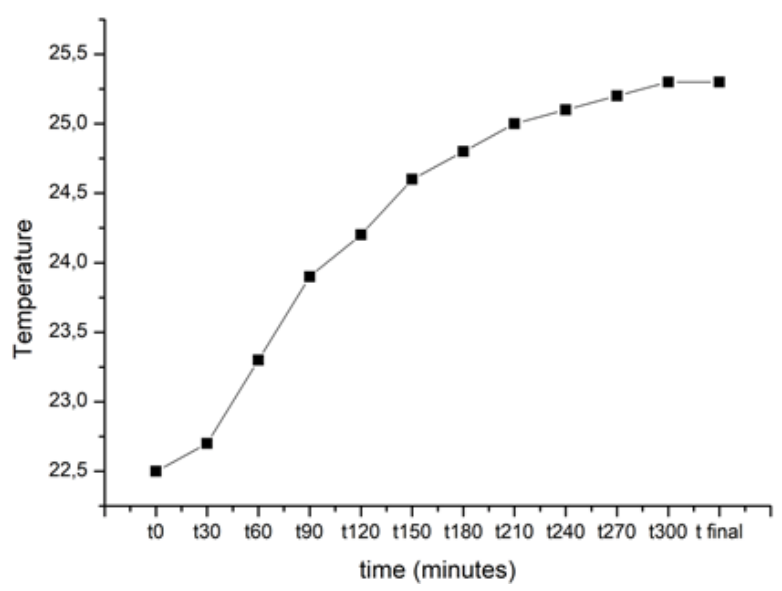

Fig. 4. Influence of temperature in the ultrafiltration process

Probably if the experiment had taken place within 8-10 hours, then the temperature would continue to increase but with very small fluctuations because when conducting the ultrafiltration process, a higher temperature than the usual room temperature would be difficult to overcome.

After analysis of figures 2, 3 and 4, it can be clearly established that the feed flow, the permeate volume obtained by the temperature and the pressure are the parameters that will always varies, because depending on the modification of one of them, the values of the other parameters will be changed automatically.

Regarding the analysis of permeate samples obtained every $30 \mathrm{~min}$, the feed solution containing humic acid recorded a conductivity value of $585 \mu \mathrm{S}$. After every $30 \mathrm{~min}$, it did not change much because the continuous recirculation of the liquid made the same homogenous solution flow through the membrane.

Finally, the same feed solution recorded the value of 415 (fig. 5). This can be explained in one way: on feeding, before the ultrafiltration process begins, the mixed solution has a certain humic acid concentration, respectively the maximum value. During the filtration, a part of the humic acid is deposited on the membrane, regardless of the fact that the flow is recirculated and over time this concentration decreases more and more, the phenomenon of dirt becoming more and more and the humic acid layer on the membrane to be more and more pronounced.

For the $585 \mu \mathrm{S}$ of conductivity in the feed solution, the humic acid retention rate was calculated on the membrane working surface, with the relation (Technical Bulletin, ultrafiltration pilot MP 90, version AM-03/2014):

$$
T R i=\left(1-\frac{C P i}{C R i}\right) x 100
$$

where: TRi represents the rate of retention or retention of the substance on the membrane, expressed in \%; CPi - the concentration of the constituent (humic acid) in the permeate; CRi - concentration of the constituent (humic acid) from the retentate.

For the 90th minute, the conductivity recorded a higher value than usual (fig. 5). This may be due to the forced penetration of humic acid through the membrane as a result of cracking it in a certain place or increasing the diameter of some pores due to the formation of a forced stream inside the membrane.

It was to somewhat expected that the conductivity would remain constant over time because the ultrafiltration process was under good conditions and this prevented the increase of the humic acid concentration in the resulting permeate samples.

Temperature plays an important role in this process, and this can also be seen in the experiment, where the

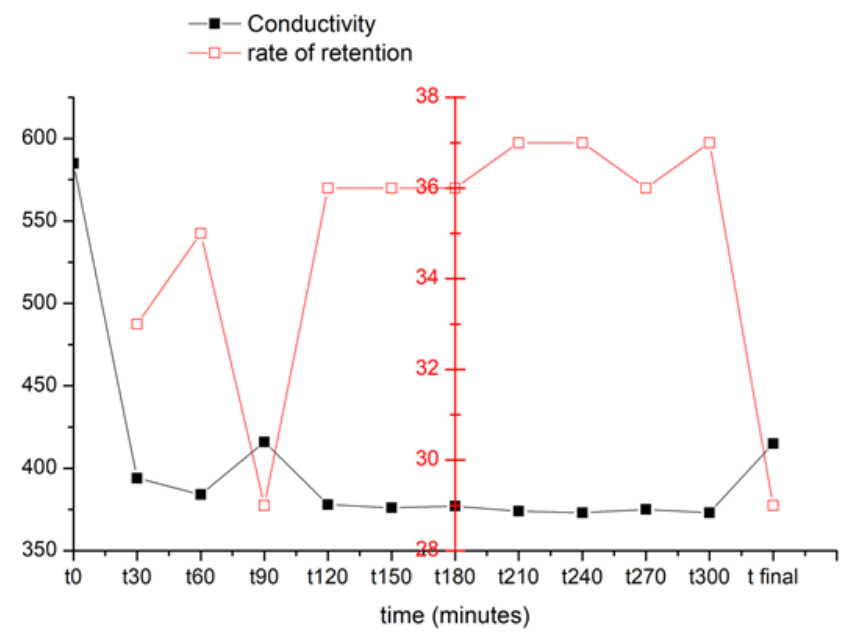

Fig. 5. Humic acid retention rate on membrane surface

concentration of humic acid is decreasing in the sample collected at the end in the feed tank. This can be explained in this way: first of all a part of the humic acid is retained on the surface of the membrane and secondly, once with the liquid recirculation, the humic acid probably dissolves more and this leads to its penetration into membrane pores, decreasing its concentration in the feed. However, in both cases it is talked about reducing the amount of humic acid to the initial amount that was introduced into the supply tank.

After the calculation, using the relation 3 , the retention rate recorded different values, shown in figure 5.

The high conductivity value in relation to the conductivity recorded in each obtained permeate sample involves increasing the retention rate of humic acid in the membrane. The highest conductivity value is indeed in the feed solution, respectively $585 \mu \mathrm{S}$ (fig. 5), then in the permeate sample harvested after min 90 and 300 at the end.

After analyzing the results obtained during $300 \mathrm{~min}$ of filtration of aqueous system containing humic acid, we can conclude that the retention rate exceeded $37 \%$. This proves that an polymeric membrane can be used in the field of ultrafiltration of aqueous system containing humic acid, both at laboratory and industrial level.

Following the humid acid-containing ultrafiltration experiments, it was found that the $\mathrm{pH}$ of the feed solution concentration was relatively low, respectively 7.4 , and would increase significantly, eventually after $300 \mathrm{~min}$ to reaches 8.5 (fig. 6). We can see that the $\mathrm{pH}$ increased as a result of the temperature increase but at the same time it continued to increase significantly after the $270 \mathrm{~min}$, despite the decrease in the temperature rise.

Dissolved oxygen (fig. 6) recorded increasing values throughout the membrane ultrafiltration process, its value fluctuating slightly in the first 10-70 min then increased by almost one $g / L$, then the small fluctuations continued to appear until the maximum value was reached in minutes 210,270 or 300 . The highest value of the dissolved oxygen was reached in the feed solution after the process ceased. This can demonstrate that its highest value can be reached when the homogenization reaches the maximum state. In the present case, the feed sample after ceasing the filtration process reached the value of $6.54 \mathrm{~g} / \mathrm{L}$.

Turbidity was measured for each sample (fig. 7), and the highest values were recorded, of course, in the initial and final concentrations, respectively 256 and 296 NTU.

In the rest, small values ranging from 0.48 to 2.99 NTU were recorded. 


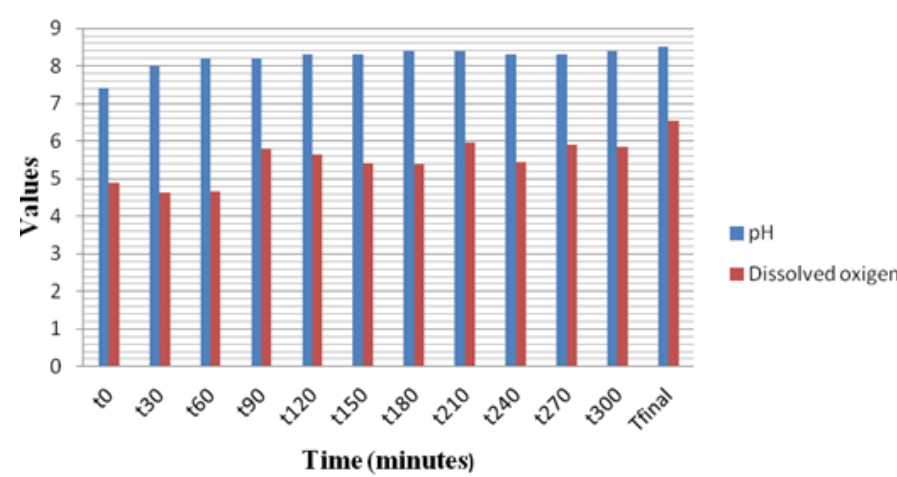

Fig. 6. pH and dissolved oxygen values for analyzed permeate samples

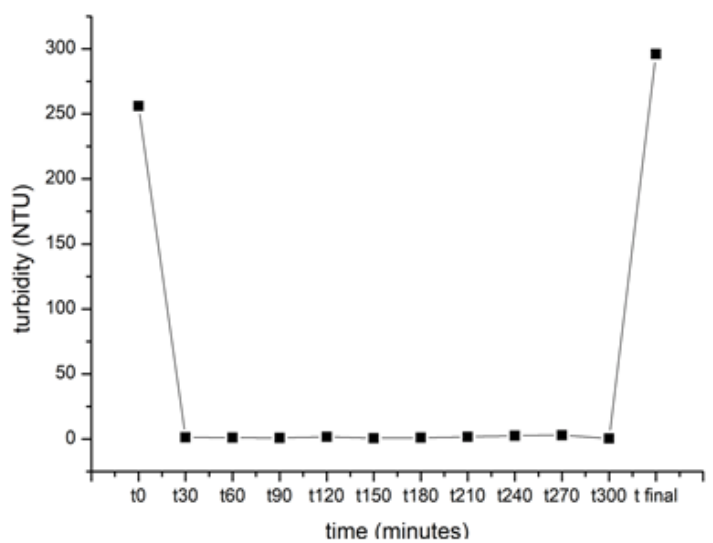

Fig. 7. Recording turbidity within 0-300 min

The low concentration of humic acid in the permeate confirms that polymeric membrane can easily retain this type of substance with very low fluctuations in turbidity.

In figure 8 are shown in combination the values of turbidity, dissolved oxygen as well as the volume of permeate obtained over a period of $300 \mathrm{~min}$, during which the membrane was continuously operated.

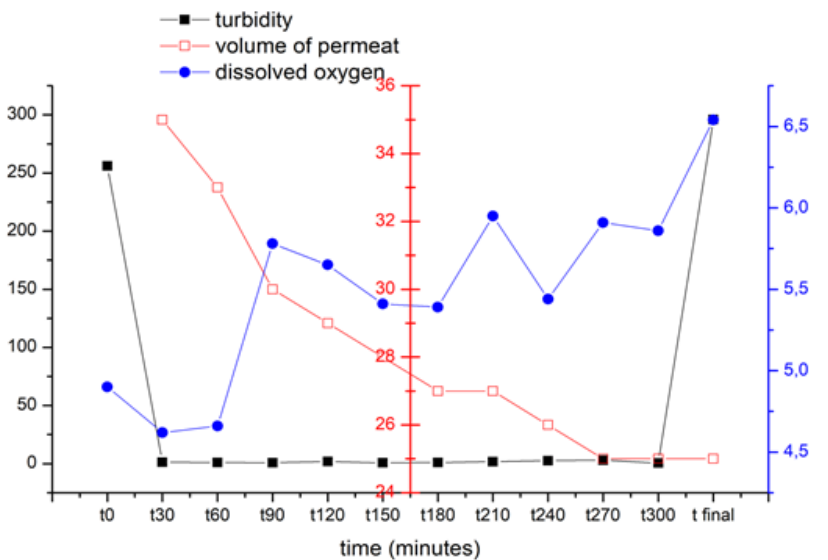

Fig. 8. Comparative discussion of the permeate samples obtained

Clear fluctuations of dissolved oxygen relative to permeate volume can be clearly seen after every $30 \mathrm{~min}$, but turbidity keeps virtually constant values, leading to the notion that regardless of the membrane inlet flow or the volume of permeate obtained, the membrane has worked the same way as well as in the first few minutes. In this case it can be stated that this type of membrane exhibits very good properties when it comes in contact with chemical substances such as humic acid, yeast, etc.

\section{Conclusions}

In this paper were presented the results obtained after an experiment that consisted in ultrafiltration of a $4 \mathrm{~g} / \mathrm{L}$ humic acid solution. The membrane used in the experiment was polymeric with a molecular weight of $13 \mathrm{kDa}$ and the purpose of this paper was to highlight the percentage of humic acid retention on its surface as well as the evolution of the most important parameters such as: liquid in the membrane, the temperature recorded during the ultrafiltration process, the pressures in the system, the volume of the permeate obtained as well as its analysis, etc.

Following the experiment, it was highlighted that humic acid favors membrane fouling and pore blockage because this type of substance contains particles of visible size even with directlook. However, turbidity values have shown that no matter how fast the fouling of the membrane occurs, the quality of the permeate remains unchanged. This is still an advantage for this type of organic membrane.

The non-modification of the transmembrane pressure during the process can be explained by the fact that a concentration of $4 \mathrm{~g} / \mathrm{L}$ of humic acid does not contribute greatly to the appearance of membrane soiling and the filtration time of the membrane is not very high.

In this case, there have been no pressures in the membrane that alter the process parameters in the experiment.

A lower concentration of humic acid in the feed sample after process end is due to its retention in the membrane, the walls of the membrane pores or the surface of the membrane, whereby the calculated retention rate reached $37 \%$. This demonstrates the recording of a positive value, advantageous in terms of membrane filtration efficiency.

The experiment in this paper has been successfully performed because its purpose was to track the percentage of humic acid that can be retained on the membrane and this has been proven by the results obtained and presented in the paper.

As a future solution for industrial applications, this type of membrane can be used in many directions or fields of activity because in contact with many types of chemicals, polyacrylonitrile has high resistance.

\section{References}

1. NAKATSUKA, S., NAKATE, I., MIYANO, T., Desalination, 106, 1996, p. 55.

2. FANE, A.G., YEO, A., LAW, A., PARAMESHWARAN, K., WICAKSANA,

F., CHEN, V., Desalination, 185, 2005, p. 159.

3. DI PROFIO, G., JI, X., CURCIO, E., DRIOLI, E., Desalination, 269, 2011, p. 128.

4. BALAN, G.G., ROSCA, I., URSU, E.L., DOROFTEI, F., BOSTANARU, A.C., HNATIUC, E., NASTASA, V., SANDRU, V., STEFANESCU, G., TRIFAN, A., MARES, M., Infection and drug resistance, 11, 2018, p.727.

5. AHMAD, A.L., MOHAMMED, H.N., SENG, O.B., PENG, L.C., Environmental Engineering and Management J ournal, 17, no. 3, 2017, pp. 723-738.

6. CHELLAM, S., JACANGELO, J.G., BONACQUISTI, T.P., Environ. Sci. Technol., 32, 1998, p. 75.

7. GU"ELL, C., DAVIS, R.H., J. Membr. Sci., 119, 1996, p. 269.

8. LI, Y., ZHANG, W., ZHANG, X., CHEN, C., WANG, J., Desalination Water Treat., 18, 2010, p. 309.

9. HUANG, H., LEE, N., YOUNG, T., GARY, A., LOZIER, J.C., JACANGELO, J.G., Water Res., 41, 2007, p. 3823.

10. XIAO, P., XIAO, F., WANG, D.-S, QIN, T., HE, S.-P., Sep. Purif. Technol., 95, 2012, p. 109.

11. DAVIS, W.M., ERICKSON, C.L., JOHNSTON, C.T., DELFINO, נ. J., PORTER, J.E., Chemosphere, 38, 1999, p. 2913.

12. WALL, N.A., CHOPPIN, G.R., Appl. Geochem., 18, 2003, p. 1573.

13. BAI, R., ZHANG, X., J. Colloid Interface Sci., 243, 2001, p. 52.

14. DONG, H.Y., GAO, B.Y., YUE, Q.Y., WANG, Y., LI, Q., Chemosphere, 130, 2015, p. 90. 
15. JEONG, K., LEE, D.S., KIM, D.G., KO, S.O., J. Environ. Sci., 26, 2014, p. 1325.

16. BARSAN, N., NEDEFF, V., TEMEA, A., MOSNEGUTU, E., CHITIMUS, A.D., TOMOZEI, C., Chemistry Journal of Moldova, 12, no. 1, 2017, p. 61.

17. KUNIGK, L., GEDRAITE, R., JURKIEWICZ, C.K., Environmental Engineering and Management J ournal, 17, 2018, p. 711.

18. MOHSEN, A., ABOOZAR, T., Environmental Engineering and Management J ournal, 17, 2018, p.551.

19. TATARU, L., NEDEFF, V., BARSAN, N., PANAINTE-LEHADUS, M., MOSNEGUTU, E., CHITIMUS, D.A, Journal of Engineering Study and Research, 22, no. 4, 2016, p. 42.

20. PINTILIE, S.C., TIRON, L.G., LAZAR, A.L., VLAD, M., BIRSAN, I.G., BALTA, S., Mat. Plast, 55, no. 1, 2018, p. 54.

21. TIRON, L.G., PINTILIE, S.C., LAZAR, A.L., VLAD, M., BALTA, S., BODOR, M., Mat. Plast, 55, no. 1, 2018, p. 95.

22. PINTILIE, S.C., TIRON, L.G., BIRSAN, I.G., GANEA, D., BALTA, S., Mat. Plast, 54, no. 2, 2017, p. 257.

23. BURUIANA, D.L., ITICESCU, C., TIRON, G.L., PINTILIE, S., SIMIONESCU, C.S., BARNAURE, M., BALTA, S., Mat. Plast, 52, no. 4, 2015, p. 608.
24. BALTA, S., BURUIANA, D.L., SIMIONESCU, C.S., TIRON, L.G., BORDEI, M., VAN DER BRUGGEN, B., Desalination and Water Treatment, 57, no. 30, 2016,p. 13924. DOI: 10.1080/19443994.2015.1062435. 25. TURA, V., TOFOLEANU, F., MANGALAGM, I., MINDRU, T.B., BRINZA, F., SULITANU, N., SANDU, I., RAILEANU, I.D., IONESCU, C., J ournal of Optoelectronics and Advanced Materials, 10, no. 12, 2008, p. 3505. 26. FURUKAWA, D., A Global Perspective of Low Pressure Membranes, National Water Research Institute, Fountain Valley, CA, 2008.

27. JACANGELO, J.G., TRUSSELL, R.R., WATSON, M., Desalination, 113, 1997, p. 119.

28. SHENG, C.G., NNANNA, A.G.A., LIU, Y.H., VARGO, J.D., Sci. Total Environ., 550, 2016, p. 1075.

29. LI, Y.H., ZHANG, X.J ., ZHANG, W., WANG, J ., CHEN, C., Desalination, 278, 2011, p. 443

30. LI, K., HUANG, T.L., QU, F.S., DU, X., DING, A., LI, G.B., LIANG, H., Desalination, 377, 2016, p. 91.

31. GUNTHER, P. SCHMITZ, C. ALBASI, C., J. Membr. Sci., 348, 2010, p. 277.

32. LI, Q.L., ELIMELECH, M., Environ. Sci. Technol., 38, 2004, p. 4683. 33. *** Ultrafiltration pilot MP 90, version AM-03/2014, Technical Book, DELTALAB SMT France.

$\overline{\text { Manuscript receivedd: } 1.08 .2018}$ 